\title{
The Study of the Distillation Volume of the Liquid Tire Pyrolysis Product
}

\author{
Elena Vasilieva ${ }^{1}$, Aleksandr Nevedrov $^{1}$, Andrey Papin $^{1}$, and Aleksandr Chernik $^{2}$ \\ ${ }^{1}$ T.F. Gorbachev Kuzbass State Technical University, 650000, Russian Federation \\ ${ }^{2}$ Belarusian state technological University, 220006 Belarus
}

\begin{abstract}
At present, the disposal of polymer and rubber waste, and especially automobile tires, is one of the most acute environmental problems. These types of waste pollute the environment both when they are stored at landfills and during subsequent disposal, especially if it is carried out in the form of incineration. Therefore, at present, much attention is paid to thermal methods of their processing. The results of the study of liquid product of pyrolysis of tires of Kuznetskecology+ LLC are presented in the work. During its distillation, the following fractures were obtained (the yield $\mathrm{wt} \%$ is indicated in parentheses): petroleum (4), gasoline (21), kerosene (18), diesel (47), fuel oil (10), for which the refractive index was determined and a conclusion about their chemical composition was drawn. When analyzing the data obtained during the analysis of liquid pyrolysis product and its fractions, as well as on the basis of published data, possible chemical reactions occurring during vulcanized rubber pyrolysis are proposed. Research results show that pyrolysis products are valuable chemical raw materials that have great prospects for industrial use, including the production of synthetic motor fuels.
\end{abstract}

\section{Introduction}

Currently, the production and consumption of products made from polymer and rubber materials is increasing every year. These products are widely used including in the mining industry (conveyor belts, car tires, etc.). Having been worn; these products are stored and then most often burnt. These processes are accompanied by significant environmental pollution, so the development of environmentally friendly technologies for rubber waste disposal is a very urgent task and attracts great attention of national and foreign scientists. The bulk of rubber waste is worn tread rubber. The total global production of tires being over 2 billion units per year; only $20-30 \%$ is recapped.

Car and dump truck tires are vulcanized rubber with various additives (metal and textile cords are used to increase the strength of tire carcass). Its interaction with oxygen during tire burning in furnaces leads to the formation of a number of toxic substances: carbon monoxide and dioxide, dioxins, sulfur oxides, furan, as well as many other harmful gases. In order to prevent the release of toxic substances into the atmosphere, a complex and expensive flue gas purification system is required, which makes the construction and operation of enterprises for the incineration of this type of waste more expensive. When 
tires are placed in landfills, toxic substances formed during the rubber destruction enter the atmosphere, soil and water, since in the presence of air rubber also oxidizes over time. In this regard, both burning and landfilling of tires are not environmentally friendly and require the development of a new method for their disposal [2]. Due to environmental hazards arising from tire burning, the European Union in 2003 adopted a special Directive prohibiting tire burning. In addition, in 2006 the European Union decided to prohibit landfilling of both whole and cut tires $[3,4]$.

Among the most diverse technologies for processing rubber waste, the most economically attractive are those that not only allow them to be disposed, but also provide valuable products. Particularly relevant are the technologies for processing this type of waste into liquid and gaseous hydrocarbon mixtures that are of a passing grade for processing at conventional oil refineries and petrochemical plants [5, 6]. In the countries of the European Union, the United States of America and Canada, a set of studies is being carried out as part of the development of modern methods for the disposal of this type of waste and enterprises that have implemented technologies for chemical processing of worn tires on an industrial scale. In Canada, the Petro Tire plant in Hamilton, Ontario annually processes 10,000 tires by pyrolysis. Target products are (product name and yield, wt\%): heating oil - 50.0; carbon black - 25.0; metal - 9.0; fiber - 5.0 [7]. In the USA it is necessary to dispose more than 250 million pieces of tires annually. Of these, American Tire Advertising (ATR) only uses 6,000 tires per year at the pyrolysis plant. The main achievement of this technology is the production of carbon black, which can be returned to process cycle and used for the manufacture of new automobile tires, thereby reducing emissions and saving resources in the production of carbon black if it were produced by the standard method [8]. In our country, a large number of studies are carried out in the field of both developing and improving technologies for processing used car tires and other types of rubber waste, but there are very few enterprises involved in this activity [9]. One of them is the company Kuznetskecology+ LLC.

In our country, rubber waste is mainly processed by thermal methods: gasification, hydrogenation and pyrolysis, since the use of these methods allows obtaining pyrolysis gas and liquid hydrocarbons, which are a valuable raw material for the chemical industry, as well as a solid residue from which a good carbon sorbent can be produced. Metal cord is also returned to process cycle and used in steel production [2].

Studying the possibility of processing liquid worn-out car tire pyrolysis product to obtain synthetic motor fuel is the main goal of our work. To achieve it, at the initial stage of the research, the problem of studying the distillation volume of the liquid tire pyrolysis product and studying the characteristics of individual fractions was solved.

\section{Materials and methods}

The liquid tire pyrolysis product for research was sampled by Kuznetskecology+ LLC in accordance with the State Standard GOST 2712-2012 "Oil and oil products. Sampling methods". Its production process at the enterprise was carried out by rubber waste heating in the absence of air to a temperature of $450^{\circ} \mathrm{C}$. The State Standard GOST 3900-85 "Oil and petroleum products. Density determination methods" was applied to determine the density of the test product. The distillation volume was determined on the basis of the State Standard GOST R 57036-2016 "Petroleum products. Determination of distillation volume at atmospheric pressure" using the ARN-LAB-1 device. The refractive indices of the obtained fractures were determined according to the State Standard GOST 18995.2-73 "Liquid chemical products. The method of determining the refractive index" using the IRF454 B2M device. 


\section{Results and discussion}

The appearance of the liquid product sampled at the enterprise is characterized by a dark brown color. The product is a homogeneous liquid without solid inclusions with a characteristic odor. The pycnometric specific gravity of the product is $0.88 \mathrm{~g} / \mathrm{cm}^{3}$.

To study the possibility of processing the liquid pyrolysis product, sampled at the enterprise, together with petroleum feeds, the temperature range of its distillation corresponding to the temperature range of oil distillation products were chosen. Distillation was carried out by a standard method at atmospheric pressure. The obtained fractures were analyzed using an IRF-454 B2M device to determine the refractive index. The research results are given in Table 1. The name of the fracture is given in accordance with the name of oil distillates.

Table 1. The results of the liquid pyrolysis product study.

\begin{tabular}{|l|c|c|c|}
\hline \multicolumn{1}{|c|}{ Fracture } & $\begin{array}{c}\text { Distillation temperature } \\
\text { range, }{ }^{\circ} \mathbf{C}\end{array}$ & $\begin{array}{c}\text { Volume, } \\
\text { wt\%. }\end{array}$ & $\mathbf{N}_{\mathbf{D}}{ }^{\mathbf{2 0}}$ \\
\hline Petroleum & H.K.(55)-100 & 4 & 1,4695 \\
\hline Petrol & $100-180$ & 21 & 1,4725 \\
\hline Kerosene & $180-240$ & 18 & 1,4660 \\
\hline Diesel & $240-350$ & 47 & 1,3885 \\
\hline Fuel oil & $>350$ & 10 & - \\
\hline
\end{tabular}

After the laboratory distillation process, the obtained fractures had the following color: petroleum - colorless, gasoline - light yellow, kerosene - yellow, diesel - red-orange, fuel oil - black. After their storage in closed glass flasks with exposure to light for 10 days, they acquired the following color: petroleum - yellow, gasoline - light raspberry, kerosene and diesel - dark raspberry, fuel oil did not change color. The color change is most likely associated with the oxidation processes of these distillates, which may indicate the presence of a large number of unsaturated compounds in the composition of the obtained distillates. Therefore, in the industrial pyrolysis product processing, the obtained distillates must be stabilized.

The data on the fractures presented in Table 1 indicate that the diesel fracture prevails in the pyrolysis product under studied ( $47 \%$ of the total mass of the product under study), gasoline and kerosene fractures are approximately equal (about $20 \%$ of the total mass).

Petroleum, gasoline and kerosene fractures have similar refractive indices, which may indicate a similarity of their chemical composition. Based on the analysis of optical characteristics, we can conclude that they contain a large number of cyclane (most likely cyclohexane) and aromatic hydrocarbons, most likely having a branched chain structure. The refractive index of the diesel fracture may indicate the presence of a large amount of alkane and alkene hydrocarbons, also branched.

The analysis of the functional groups of the fractures was determined by IR spectroscopy using an Agilent Cary 630 FTIR IR Fourier spectrometer in the range 4000$650 \mathrm{~cm}^{-1}$. The research results are presented in Fig. 1-4. 


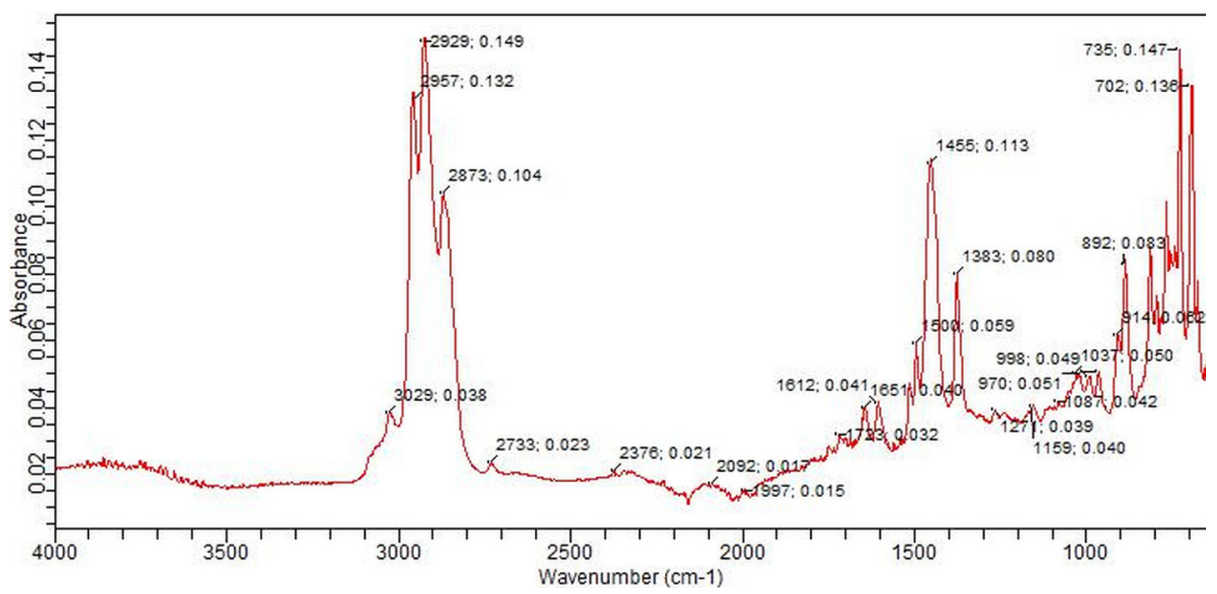

Fig. 1. IR spectrum of the fracture $100-180^{\circ} \mathrm{C}$.

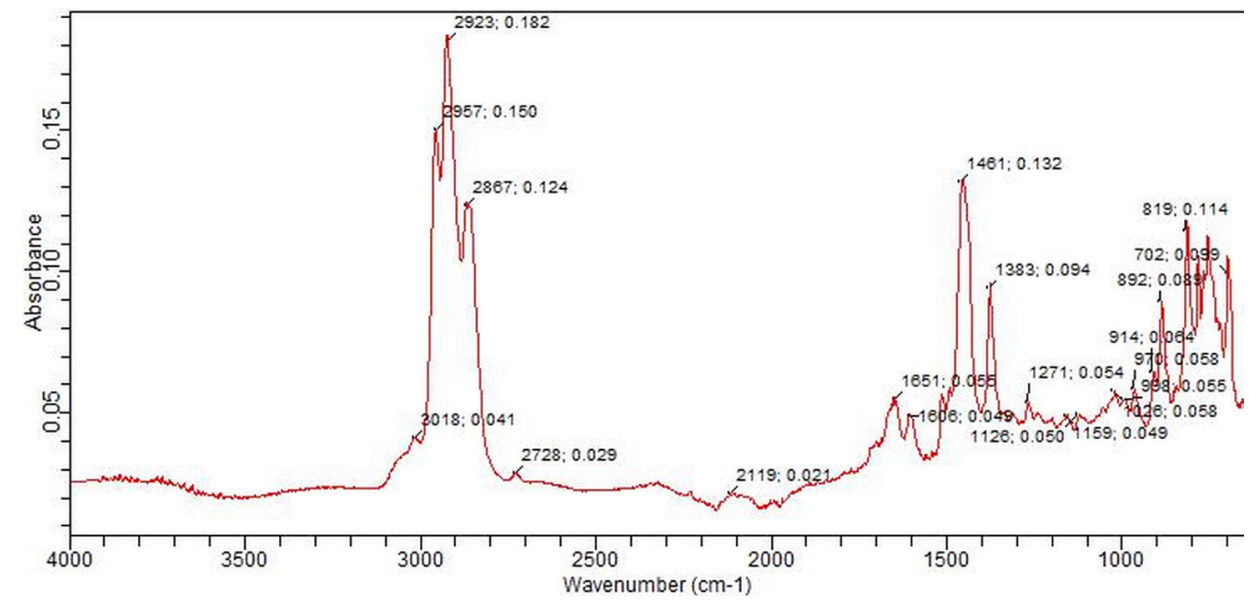

Fig. 2. IR spectrum of the fracture $180-240^{\circ} \mathrm{C}$.

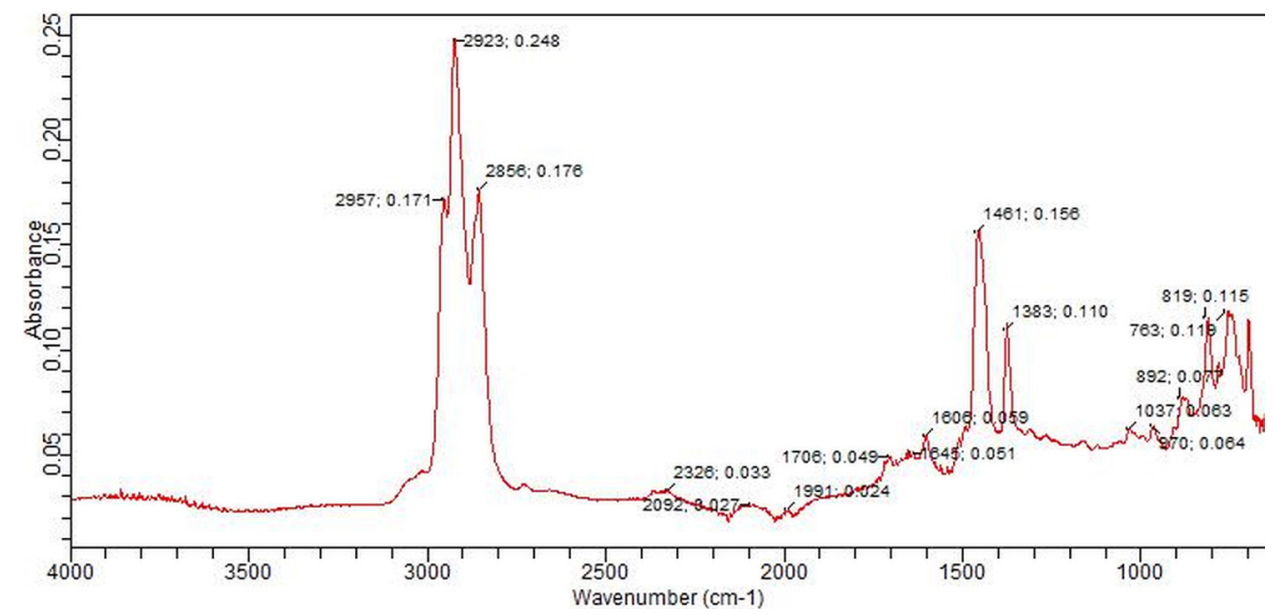

Fig. 3. IR spectrum of the fracture $240-350^{\circ} \mathrm{C}$. 


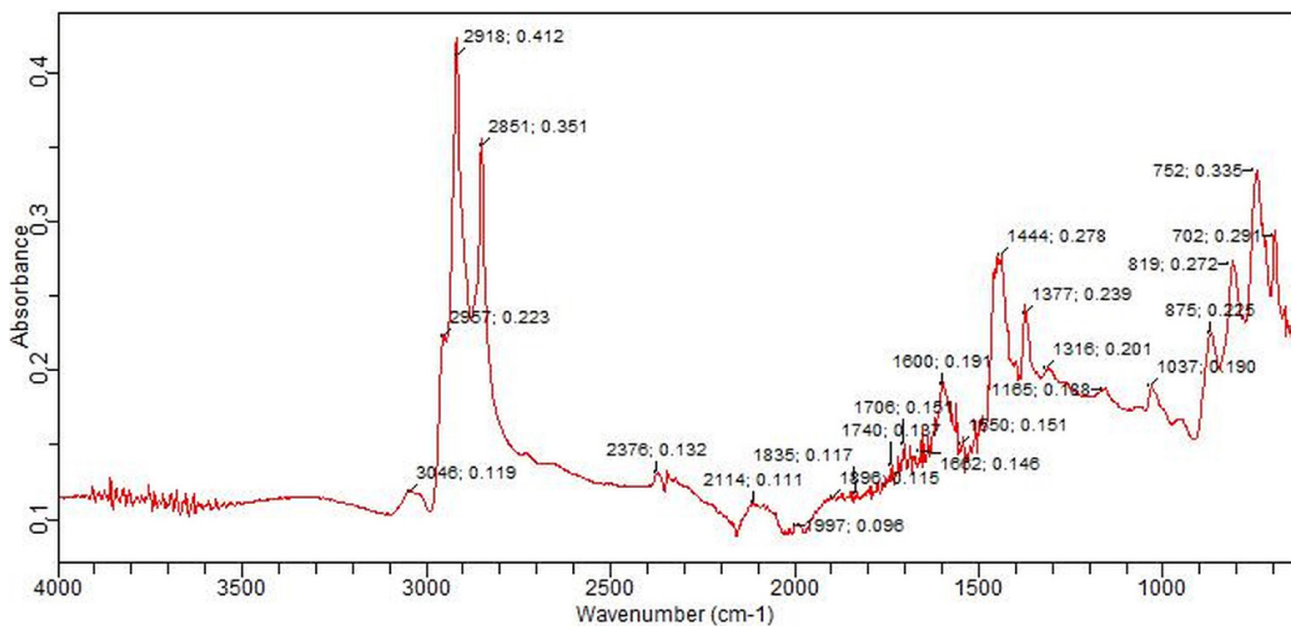

Fig. 4. IR spectrum of the fracture $>350{ }^{\circ} \mathrm{C}$.

The position of the stretching vibration bands of $\mathrm{CH}_{3}$ groups corresponds to 2929, 2923, $22918 \mathrm{~cm}^{-1}$. Intense peaks having values of 1456, 1461, 1444 are associated with the aromatic ring vibrations.

In the spectra, the absorption bands in the range $1370-750 \mathrm{~cm}^{-1}$ characterize the deformation vibrations of $\mathrm{C}-\mathrm{H}$ and $\mathrm{C}-\mathrm{C}$ bonds of alkanes, naphthenes, and arenes.

It was found that when the sample is heated to a temperature of $350{ }^{\circ} \mathrm{C}$, its chemical composition and structure change due to the polymerization of the resinous components of oil products.

\section{Conclusion}

The results obtained in the study of pyrolysis liquid confirm the conclusions presented in [10] on the process of vulcanized rubber pyrolysis through the breaking of backbone and side chains of its molecules, both double and single with the formation of hydrogen radicals, saturated and unsaturated hydrocarbons, carbon and sulfur. Further, hydrogenation, addition and redistribution reactions can occur in these products. The diene synthesis reactions occurring during pyrolysis and involving unsaturated hydrocarbons cause the formation of aromatic compounds that make up pyrolysis liquid.

The analysis of the research results showed that pyrolysis liquid formed during tire processing is a valuable raw material both for the production of synthetic motor fuels and for the recovery of valuable chemicals.

\section{References}

1. A. S. Maloletnev, Solid Fuel Chemistry, 44, 3 (2010)

2. A. V. Yatsun, N. P. Konovalov, I. S. Efimenko, Solid Fuel Chemistry, 47, 4 (2013)

3. O. A. Pikhl', Yu. Kh. Soone, L. V. Kekisheva, M. A. Kaev, Solid Fuel Chemistry, 47, 3 (2013)

4. Hazardous Waste Directive 91/689/EEC

5. Kh. M. Kadiev, A. U. Dandaev, A. M. Gyul'maliev, A. E. Batov, S. N. Khadzhiev, Solid Fuel Chemistry, 47, 2 (2013)

6. P. T. Williams, S. Besler, D. T. Tailot, Fuel, 69 (1990) 
7. H. Hotzon, Gummibereifung. 65, 7 (1998)

8. E. E. Gorlova, B. K. Nefedov, E. G. Gorlov, Solid Fuel Chemistry, 43, 4 (2009)

9. A. V. Papin, A. Yu. Ignatova, E. A. Makarevich, A. V. Nevedrov, D. A. Martsiyash, A. V. Loginova, E. V. Vasileva, T. G. Cherkasova, S. P. Subbotin, Coke and Chemistry, 62, 2 (2019)

10. A. V. Yatsun, P. N. Konovalov, N. P. Konovalov, Solid Fuel Chemistry, 42, 3 (2008) 